\title{
Astroglial Modulation of Transient Potassium Current Development in Cultured Mouse Hippocampal Neurons
}

\author{
Rui-Lin Wu and Michael E. Barish \\ Division of Neurosciences, Beckman Research Institute of the City of Hope, Duarte, California 91010
}

Hippocampal neurons exhibit three voltage-gated potassium currents, two transient currents and a delayed rectifier, that influence numerous aspects of electrogenesis including action potential duration and accommodation to sustained depolarization. These currents, termed A-, D-, and K-currents, respectively, can be distinguished based on kinetics, steady state inactivation characteristics, and sensitivity to 4-aminopyridine (see Wu and Barish, 1992b). We have compared the voltage-gated potassium currents in voltageclamped pyramidally shaped cultured hippocampal neurons growing on or touching glial fibrillary acidic protein-expressing astroglia (termed on-glia or touching-glia neurons, respectively) with those in similar neurons growing directly on a coated glass substrate (termed off-glia neurons). We observed differences in the wave forms of total potassium current that correlated with the extent of astroglial contact. After 5-7 d in culture, A-current amplitude in off-glia neurons was approximately $19 \%$ of that of neurons growing in the normal (for culture) on-glia configuration. D-current amplitude tended to be larger in these off-glia neurons. Neurons in contact with astroglia had greater membrane area than off-glia neurons. Comparison of current densities (current at a fixed voltage normalized to capacitance and expressed in units of $\mathrm{pA} / \mathrm{pF}$ ) indicated that A-currents were the major component of transient potassium current in on- and touchingglia neurons, while D-currents were more dominant in offglia neurons.

Astroglia influenced membrane currents by a surface- or extracellular matrix-associated mechanism, rather than by free diffusion of a soluble factor, as differences were observed between closely adjacent neurons on the same coverslip. Living glia were required, as potassium currents in neurons grown on dried or methanol-fixed glia resembled those of off-glia neurons. On-glia neurons in cultures treated with an RNA synthesis inhibitor [DRB (5,6-dichloro-1- $\beta$-Dribofuranosylbenzimidazole)] for 5-7 d had reduced wholecell capacitance and A-current amplitude. This effect was localized to DRB actions on underlying astroglia, not on the neurons.

Action potentials elicited by current injection varied with astroglial contact. In on-glia neurons with relatively larger

\footnotetext{
Received Feb. 26, 1993; revised Aug. 24, 1993; accepted Aug. 31, 1993.

We thank Dr. R. Hammerschlag for assistance with measurement of RNA synthesis, Drs. G. Laurent and K. J. Seymour-Laurent for comments on the manuscript, and Ms. J. Flanagan for assistance in its preparation. This work was supported by grants from the NSF (IBN9121751) and NIH (NS23857). M.E.B. is an Established Investigator of the American Heart Association.

Correspondence should be addressed to Michael E. Barish at the above address. Copyright (C) 1994 Society for Neuroscience $0270-6474 / 94 / 141677-11 \$ 05.00 / 0$
}

A-currents a delay was seen in the onset of firing after depolarization. In contrast, action potentials in off-glia neurons rose smoothly after initiation of depolarization.

We conclude that astrocytes modulate the appearance of transient potassium currents in hippocampal pyramidal neurons by inducing development of A-current. Increased A-current amplitude was associated with an increase in membrane area; this observation suggests the possibility that glia promote insertion of A-current-rich membrane. Signals appear to pass from astroglia to neurons by contact or short-range diffusion. We propose astroglial-induced plasticity of A-current as a mechanism for long-term modulation of hippocampal neuron excitability.

IKey words: A-current, D-current, K-current, potassium currents, neuronal development, ion channels, astroglia, neuron-glia interactions]

The activation of transient potassium currents (Hagiwara et al., 1961; Connor and Stevens, 1971a; Neher, 1971; for reviews, see Rogawski, 1985; Rudy, 1988) in hippocampal neurons (Gustafsson et al., 1982; Segal and Barker, 1984; Segal et al., 1984; Zbicz and Weight, 1985; Halliwell et al., 1986; Nakajima et al., 1986; Neumann et al., 1987; Storm, 1988; Ficker and Heinemann, 1992; Wu and Barish, 1992b) influences both action potential wave forms and patterns of repetitive firing (Segal et al., 1984; Halliwell et al., 1986; Nakajima et al., 1986; Storm, $1987,1988)$. Rodent hippocampal neurons express two transient potassium currents, termed $\mathrm{A}$ - and D-currents, that can be separated based on kinetics, voltage dependence, and pharmacological sensitivities (Storm, 1988; Ficker and Heinemann, 1992; Wu and Barish, 1992b). Despite their importance as regulators of excitability, little is known about the control of the appearance of these transient potassium currents during development.

The appearance of A-currents in hippocampal neurons may be regulated by influences that vary during the initiation and growth of neurons in dissociated cell culture. This period often consists of plating onto an inert substrate followed by astroglial proliferation, neurite growth, and neuronal maturation. In hippocampal CA1 pyramidal neurons of acute slices from mature rat (Storm, 1988), or acutely dissociated neurons from mouse embryos (15-16 d gestation; Wu and Barish, 1992b), or neurons isolated from embryonic rat hippocampus and grown for more than 1 week in culture (Ficker and Heinemann, 1992), A-currents comprise greater than $70 \%$ of total peak transient potassium current. In contrast, in embryonic mouse hippocampal neurons cultured on polylysine-coated glass for 2-3 d, or in cultured embryonic rat hippocampal neurons examined within $4 \mathrm{~d}$ of dissociation, A-currents comprise less than half of total 
transient potassium current (Ficker and Heinemann, 1992; Wu and Barish, 1992b). This pattern is seen in measures of absolute current amplitudes, and in current densities (current amplitudes normalized to membrane area measured as whole-cell capacitance). The relative deficit of A-current in neurons after short periods in culture suggests regulation associated with loss of the in vivo environment.

This report is part of an effort to identify potential regulatory influences on potassium currents. We here present evidence indicating that, in culture, contact with astroglia supports appearance of A-type transient potassium currents in developing hippocampal neurons. Specifically, we show that the presence of A-current during neuronal growth in culture is correlated with the extent of contact with astroglia, that only living astroglia are competent to support $\Lambda$-currents, and that this ability is blocked by inhibition of astroglial RNA synthesis during the first $24 \mathrm{hr}$ of culture. These experiments thus suggest that astroglia actively participate in developmental regulation of transient potassium current during neuronal differentiation.

Some of these results have recently been presented in abstract form (Wu and Barish, 1992a).

\section{Materials and Methods}

Preparation of cultures. Procedures for preparation of cultured hippocampal neurons from mouse embryos at 15-16 d gestation were based on classical descriptions (Banker and Cowan, 1977) and are described in detail in a previous publication (Wu and Barish, 1992b). Briefly, dissociated hippocampal cells were grown in serum-containing medium on 12-mm-diameter glass coverslips coated with poly-D-lysine and in some cases laminin. They were treated with antimitotic (cytosine arabinoside or fluorodeoxyuridine) at $24 \mathrm{hr}$, which resulted in appearance of an incomplete astroglial monolayer after 5-7 d. Cell density was greatest in central regions of coverslips because cells were applied to the coverslips as a bubble, and medium was added after the cells had settled onto the substrate. Thus, on-glia neurons tended to be found toward the centers of the cover slips, while off-glia neurons were found closer to the edges.

Electrophysiological measurements. Whole-cell patch gigaohm seal techniques were standard (Hamill et al., 1981). Recordings were made using an Axopatch 1B amplifier and pCLAMP acquisition and analysis software (both from Axon Instruments). Leak and capacitative currents were subtracted on line by a combination of analog compensation in the amplifier and a $P /-8$ digital subtraction scheme in the acquisition software. In the latter, currents recorded during eight voltage steps of one-eighth amplitude and opposite sign as the test pulse were summed and added to the experimental trace. Total membrane capacitance was determined by integrating capacity transients recorded immediately after entering the whole-cell configuration during $10 \mathrm{mV}$ depolarizations from $-80 \mathrm{mV}$. Input resistance was determined from the steady state current recorded during these same depolarizations after capacity transients had settled.

For recording voltagc-gated potassium currents under voltage clamp, the internal solution contained (in $\mathrm{mm}$ ) $65 \mathrm{KCl}, 65 \mathrm{KF}, 1 \mathrm{CaCl}_{2}, 2$ $\mathrm{MgCl}_{2}, 11$ EGTA, 10 HEPES at $\mathrm{pH} 7.3$, and the external solution [based on Hanks' balanced salt solution (BSS)] contained (in mM) $140 \mathrm{NaCl}$, $5.8 \mathrm{KCl}, 1.8 \mathrm{CaCl}_{2}, 1 \mathrm{MgCl}_{2}, 4.2 \mathrm{NaHCO}_{3}, 5.5$ glucose, 15 HEPES at $\mathrm{pH}$ 7.3. This internal solution blocked activation of Ca currents and Ca-dependent currents (R.-L. Wu and M. E. Barish, unpublished observations). External solutions contained tetrodotoxin (TTX; $0.5-1 \mu \mathrm{M}$ ) to block transient and sustained sodium currents (for review, see Brown et al., 1990). Under our recording conditions all voltage-gated potassium currents could be accounted for by the combination of the two transient currents (A- and D-currents), and a delayed rectifier-like current ( $K$ current) showing minimal inactivation (Wu and Barish, 1992b). These voltage-gated potassium currents have properties similar to those recently revicwed by Storm (1990). For recording action potentials under current clamp, the internal solution contained $124 \mathrm{~mm} \mathrm{KCl}$ and $6 \mathrm{~mm}$ $\mathrm{KF}$ with other components unchanged, and the external solution was identical except that TTX was eliminated. Voltages were corrected for liquid junction potentials between internal and external solutions.
As in our previous investigation (Wu and Barish, 1992b), recordings were made from neurons identified as pyramidal based on the presence of a triangular perikaryon with one prominent apical dendrite and several shorter basilar dendrites (see also Banker and Cowan, 1979; Kriegstein and Dichter, 1983). Examples of the neurons studied are shown in Figure 1. Astroglia were identified during experiments by their appearance, under these serum-containing growth conditions, as thin flat cells underlying neurons. These cells were selectively stained by antibody against glial fibrillary acidic protein (GFAP), a marker of astroglia (Bignami et al., 1972). Recordings were made at room temperature.

The analysis of transient potassium currents would be complicated by inadequate control of membrane voltage. However, two characteristics of the A-currents recorded from these cells indicated that space clamp was sufficient for this investigation. First, the forms of A-current $I-V$ relations (see Fig. 4) and steady state inactivation curves (see Fig. 6) were similar for on- and off-glia neurons; the differences observed were quantitative rather than qualitative. Second, in our previous investigation of transient potassium currents during first $3 \mathrm{~d}$ of culture (Wu and Barish, 1992b), we did not observe changes in the voltage dependencies of transient potassium current activation and inactivation during an early period of neurite outgrowth. As onc might expect that inadequate space clamp would manifest itself as shifts in voltage dependence correlated with cell age and membrane capacitance, we concluded that an adequate space clamp was attained.

Measurement of RNA synthesis. Mixed neuron-glia cultures ( $24 \mathrm{hr}$ in vitro) were employed. Experimental cultures were pretreated with DRB (5,6-dichloro-1- $\beta$-D-ribofuranosylbenzimidazole; $32 \mu \mathrm{M}$ ) for $2.5 \mathrm{hr}$ before ${ }^{3} \mathrm{H}$-uridine $(100 \mu \mathrm{Ci} / \mathrm{ml})$ was added to both control and experimental cultures. After $12 \mathrm{hr}$ under normal growth conditions, cultures were rinsed in Hanks' BSS ( $5 \mathrm{~min}$ ), treated with trichloroacetic acid $(5 \%)$, and dissolved in TS- 1 tissue solvent before measurement of incorporated radinactivity by scintillation.

DRB was obtained from Sigma and diluted in ethanol to make a 32 mM stock, which was stored at $-20^{\circ} \mathrm{C}$. This stock was diluted $1: 1000$ into experimental cultures.

Statistical tests. Significance was assessed using two-tailed $t$ test for unpaired data. Results were considered significant at $p<0.05$.

\section{Results}

We have previously reported that the macroscopic transient potassium currents (A-current and D-current) in pyramidally shaped hippocampal neurons dissociated at embryonic day 1516 and placed into culture changed markedly during the first 3 $\mathrm{d}$ in vitro (Wu and Barish, 1992b). During this initial period in cell culture, when neurons have relatively little contact with glial cells, the proportion of total transient potassium current identified as A-current declined from greater than $80 \%$ immediately after dissociation to less than $40 \%$. In the present study we have examined neurons in culture for $5-7 \mathrm{~d}$, a period during which neurons come into contact with, and start to grow on, an expanding astroglial monolayer covering 30-60\% of the substrate. We observed that during this period the presence of $\mathrm{A}$ and D-currents in neurons depended on the extent of contact with underlying or nearby astroglial cells. In the sections that follow (1) the voltagc-gated potassium currents in neurons growing on or touching astroglia are compared to those growing on the coated glass substrate, (2) living versus fixed or dried glia are evaluated as substrates for appearance of neuronal potassium currents, and (3) the consequences of inhibition of RNA synthesis in neurons and glia on the development of potassium currents are described.

\section{Potassium currents in on-, touching-, and off-glia neurons}

The micrographs in Figure 1 illustrate pyramidally shaped neurons from the same coverslip considered to be on-glia, touchingglia, or off-glia neurons for the purposes of this investigation. Two examples are given for each case. Off-glia neurons had no 


\section{Off-glia}
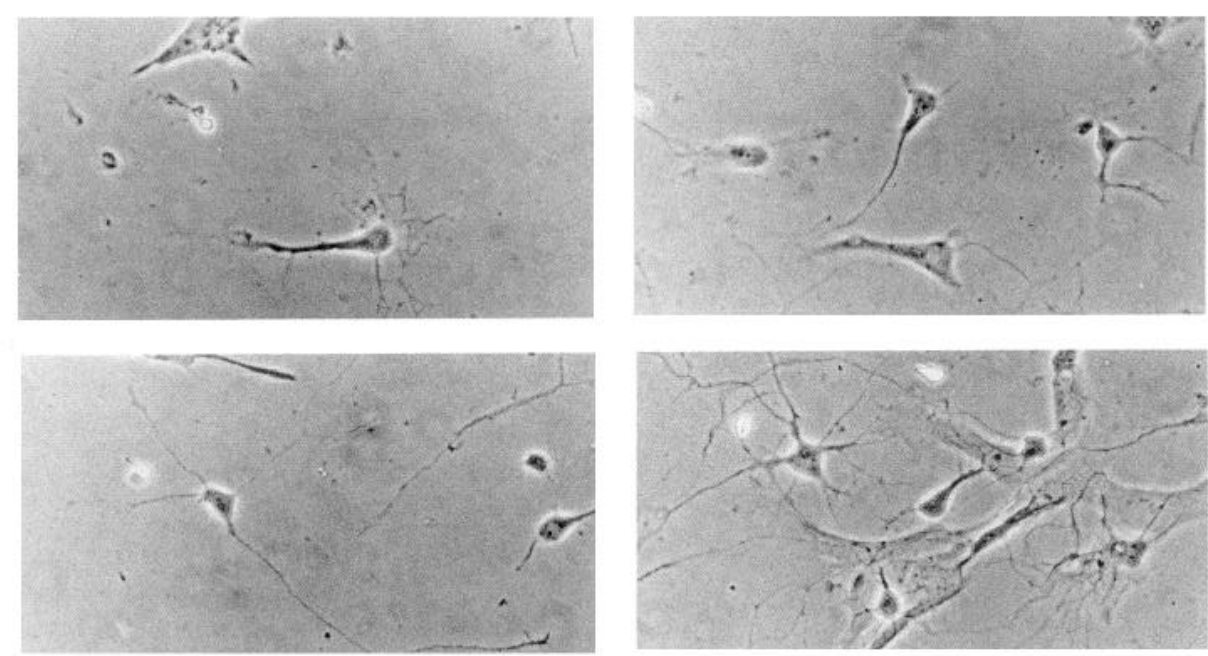

Touching-glia

Figure 1. Phase-contrast micrographs illustrating the appearances of neurons growing on the polylysine/laminin-coated glass substrate (Off-glia), neurons with somata on the substrate but with neurites growing across glia (Touching-glia), and neurons growing with somata on top of glia (Onglia). The extent of glial contact varied considerably for the touching-glia class of neurons. In the upper touching-glia panel, the contact of the small process with the adjacent glial cell was sufficient to alter expression of transient potassium currents. Neurons were photographed from the same coverslip, and had been in culture for $72 \mathrm{hr}$. They were treated with an antimitotic at $24 \mathrm{hr}$. Scale bar, $50 \mu \mathrm{m}$.

detectable contact with any non-neuronal cells, while on-glia neurons had their cell bodies and virtually all of their neuritic field on glial cells. Touching-glia neurons had their cell bodies on the noncellular substrate, and some contact between neurites and glia. As illustrated by the two examples of touching-glia neurons, the extent of glial contact for neurons in this category could vary considerably.

The flat non-neuronal cells in these cultures were predominately astroglia, as cultures were grown in serum-containing medium that promotes proliferation of immature astroglia, and these non-neuronal cells displayed immunoreactivity against GFAP (Bignami et al., 1972).

To provide an indication of the relative health of on-, touching-, and off-glia neurons, we compared their resting electrical properties (Fig. 2). While whole-cell capacitance (used as an index of membrane area) increased with degree of neuron-astroglia contact, and input resistance was smaller in the larger on-glia neurons, there was no significant difference in input conductance density at $-80 \mathrm{mV}$ (conductance was normalized to capacitance, noted as specific conductance and expressed as $\mathrm{pS} / \mathrm{pF}$ ) between these classes of neurons. Thus, while on-glia neurons were larger than touching- or off-glia neurons, as expected given the known growth-promoting activities of glial monolayers (Noble et al., 1984; Fallon, 1985; Pixley et al., 1987), to the extent that resting conductance is an indicator of cell health the three classes of neurons were equivalent.

The wave forms of potassium currents recorded from on-, touching-, and off-glia neurons showed characteristic differences. As illustrated by the traces shown in Figure 3, when recordings were made following conditioning hyperpolarizations to $-120 \mathrm{mV}$, a fast transient component present in onglia neurons was reduced in touching-glia neurons and absent from off-glia neurons (upper traces). In contrast, recordings made from the same cells following a conditioning depolarization to $-40 \mathrm{mV}$ lacked this rapidly relaxing component (lower traces). Since steady state inactivation of A-current in mouse hippo- campal neurons is essentially complete at $-40 \mathrm{mV}$ (Wu and Barish, 1992b), the fast transient component of potassium current that varied with astroglial contact was considered to be A-current.

Isolation of the A-currents from these neurons as the transient currents sensitive to a conditioning depolarization to $-40 \mathrm{mV}$ revealed a fast inactivating current that was largest in the onglia neuron (Fig. 4A). Consideration of the current-voltage ( $I-$ $V$ ) relations for these cells (Fig. $4 B 1$ ) and for a population of cells (Fig. 4B2) indicated that the A-current activation threshold was between -50 and $-40 \mathrm{mV}$ regardless of the extent of astroglial contact. Further, the shapes of the A-current $I-V$ relations were similar for the three classes of cells. Note in particular
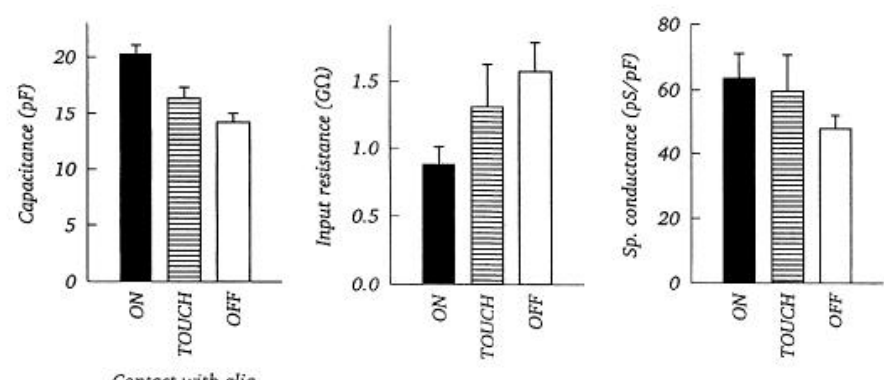

Figure 2. Resting properties of on-, touching, and off-glia neurons studied after 5-6 d in culture. Input resistance was determined from the steady state current measured during $10 \mathrm{mV}$ excursions from the holding potential $(-80 \mathrm{mV})$. Whole-cell capacitance, used as an index of membrane area, was determined by integrating the increment in capacity transient seen on passing from the on-cell to the whole-cell recording configuration. Resting conductance density is the ratio of input conductance near the holding potential to the whole-cell capacitance, and is noted as specific conductance. Data are mean \pm SEM; $n=8$ for on-glia, 6 for touching-glia, and 6 for off-glia neurons; for off-glia versus on-glia, $p<0.05$ for input resistance and cell capacitance, not significant for specific input conductance. 
Figure 3. Variation in voltage-gated potassium currents between on-, touching-, and off-glia neurons similar to those illustrated in Figure 1. Shown are families of currents recorded at voltages between -50 and $+40 \mathrm{mV}$ following 1 -sec-long conditioning hyperpolarizations to $-120 \mathrm{mV}\left(V_{C}=-120 \mathrm{mV}\right.$; upper traces) or 500-msec-long conditioning depolarizations $-40 \mathrm{mV}\left(V_{C}=\right.$ $-40 \mathrm{mV}$; lower traces). Previous studies have demonstrated that a prepulse to $-40 \mathrm{mV}$ is sufticient to inactivate A-current selectively ( $\mathrm{Wu}$ and Barish, 1992b). Internal and external solutions served to inhibit sodium, calcium, and calcium-dependent currents (see Materials and Methods)
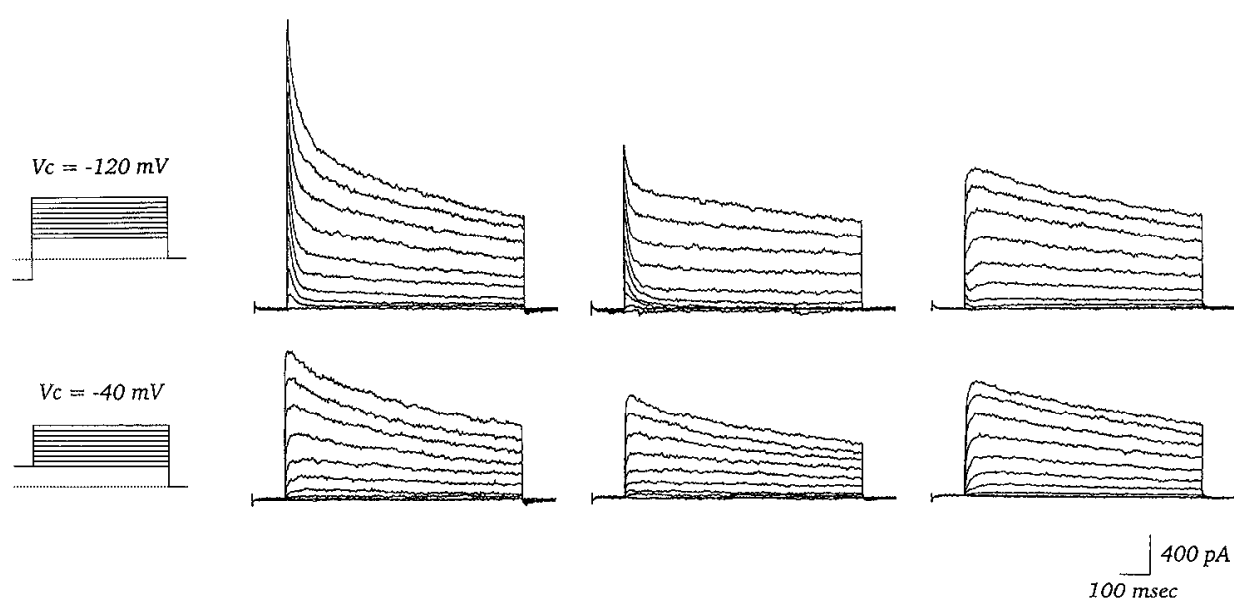

that the A-current $I-V$ relation for off-glia neurons when appropriately scaled (open squares in Fig. 4B2) essentially superimposed on those for on- and touching-glia neurons.

The contributions of A- and D-currents to the wave form of total potassium current were quantitatively analyzed using two procedures: (1) separation of voltage-gated potassium currents based on steady state inactivation and on differential sensitivity to 4-aminopyridine (4-AP), and (2) decomposition of steady state inactivation curves into two distinct components corresponding to A- and D-currents. Data illustrating the efficacy of these procedures were presented in our previous publication (Wu and Barish, 1992b), and they are described in more detail below.

The upper row of Figure 5 shows the magnitudes of peak total potassium current recorded at $+40 \mathrm{mV}$, and of each class of potassium current separated using the first procedure (mean \pm SEM, $n=4-6$ in each case). In this scheme, A-current was taken to be the current sensitive to a 500-msec-long conditioning depolarization to $-40 \mathrm{mV}$, and D-current to be the current sensitive to $100 \mu \mathrm{M}$ 4-AP. Peak current amplitude was similar in on- and touching-glia neurons, and smaller in off-glia neurons. Separation of the individual currents indicated that peak potassium current amplitude in off-glia neurons was reduced in large part because in these cells A-current amplitude was only $19 \%$ of that in on-glia neurons. At the same time D-current amplitude was increased (to $186 \%$ of on-glia neurons), but not sufficiently to compensate completely for the reduced A-current. When the current amplitudes were divided by cell capacitance to normalize for differences in membrane area (current densities noted as specific currents in $\mathrm{pA} / \mathrm{pF}$; lower row of Fig. 5), total

Figure 4. A, A-currents isolated from the traces shown in Figure 3 by pointby-point subtraction of the currents recorded following a conditioning depolarization to $-40 \mathrm{mV}$ from those recorded following a conditioning hyperpolarization to $-120 \mathrm{mV}$. This procedure yielded rapidly inactivating potassium currents that were insensitive to concentrations of 4-AP (100$200 \mu \mathrm{M})$ sufficient to block D-currents (Fig. $\mathrm{l}$ of $\mathrm{Wu}$ and Barish, 1992b). In some cells an additional noninactivating current was seen; it has not been further analyzed. In $B$, peak current amplitudes from $A$ have been plotted. A transient component could be identified in all three cases (in the off-glia cell it is evident at more negative voltages), and the noninactivating current has been ignored. $B I, I-V$ relations for the A-currents shown in $A . B 2$, Plot of A-current density $(\mathrm{pA} / \mathrm{pF})$ versus voltage for on-, touching- and off-glia neurons (mean \pm SEM, $n=6-8$ for each category). Current densities were plotted to facilitate comparison between neurons of different sizes. The curve for off-glia neurons was further scaled to show that it followed the same trajectory as those for on- and touching-glia neurons. A-current was isolated as in Fig. 3.

A
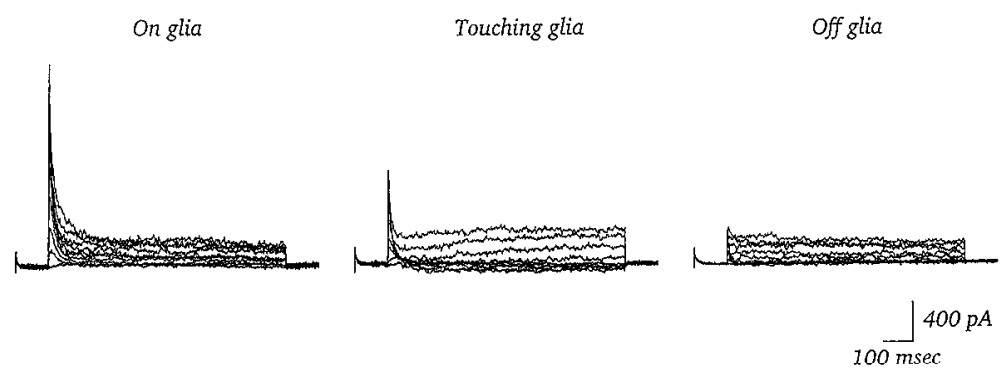

B1

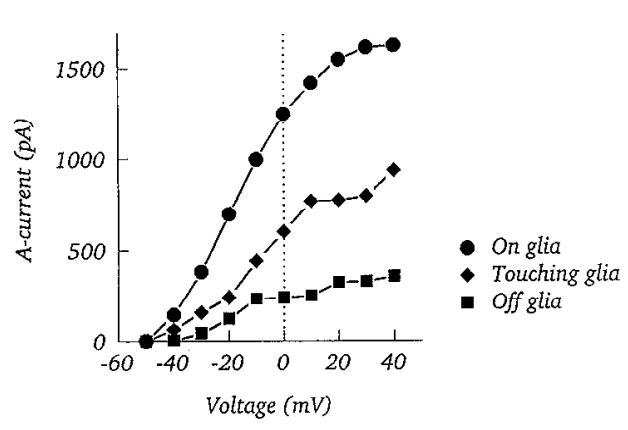

B2

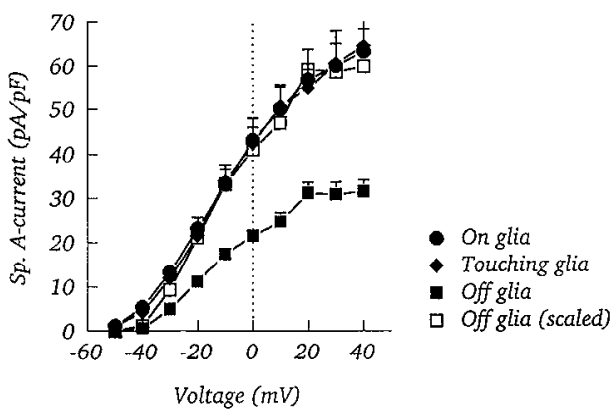



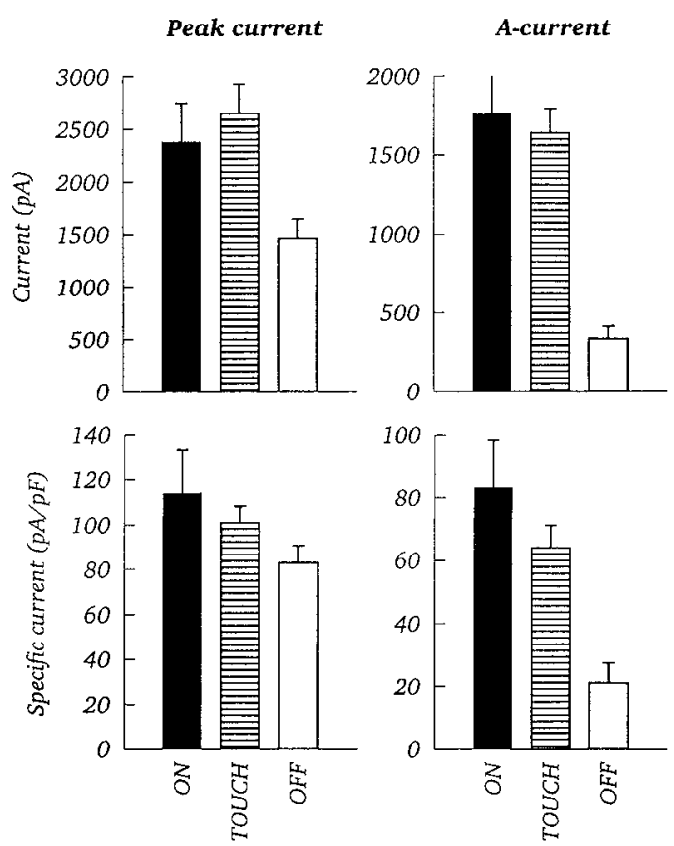

Contact with glia
D-current
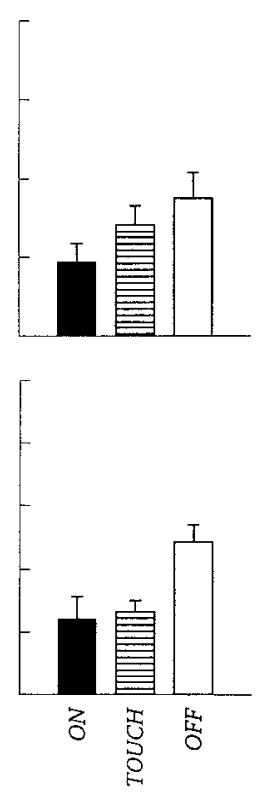

K-current
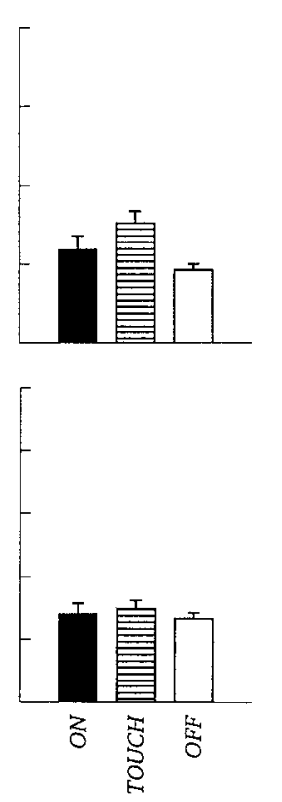

Figure 5. Peak potassium current, and A-, D-, K-currents, isolated from on-, touching-, and off-glia neurons. The upper row shows absolute current amplitude (pA); in the lower row these same data have been normalized to wholecell capacitance $(\mathrm{pA} / \mathrm{pF})$. A-current was isolated as the rapidly inactivating current sensitive to a conditioning depolarization to $-40 \mathrm{mV}$. D-current was isolated as the more slowly inactivating current sensitive to block by $100 \mu \mathrm{M}$ 4-AP. K-current was taken to be the noninactivating current insensitive to both conditioning depolarization and 4-AP. Data are mean \pm SEM; $n=4-6$ cells in each category. Both A-current amplitude and density (specific current) were significantly reduced in off-glia as compared to on-glia neurons ( $p<0.01$ and $p<0.02$, respectively). D-current amplitude and density were increased in off-glia as compared to on-glia neurons, but only the change in current density reached significance $(p<0.05)$. potassium current density did not differ significantly between the three classes of neurons. However A-current density was highest in on-glia neurons, and D-current density was highest in off-glia neurons. K-current density was similar in all three classes of neurons.

Comparison of the current amplitudes with the current densities in Figure 5 suggests that while total potassium current density remained constant, the presence of additional membrane in on-glia neurons (capacitance data in Fig. 4) was accompanied by a disproportionate increase in A-current amplitude (see Discussion).

Illustrated in Figure 6 is separation of the contributions of Aand D-currents to total relaxing current in the three classes of neurons evaluated using the second procedure based on differences in steady state inactivation curves. Since the half-inactivation voltage for A-current is approximately $75 \mathrm{mV}$ negative to that of D-current (Wu and Barish, 1992b), plots of total inactivating current availability versus voltage $\left(I / I_{\max }\right)$ show two inflection points. The proportion of the total inactivation curve attributable to $\mathrm{A}$ - or D-currents was determined from these inactivation curves by using a least-squares regression routine to fit two Boltzmann relations with fixed parameters appropriate for A- and D-currents. Since adequate fits were obtained by varying anly the relative power of the two Boltzmann relations, we concluded that the steady state inactivation properties of the three classes of cells could be described by an additive mixture of those for A- and D-currents. The relative contributions of Aand D-currents obtained using this procedure were similar to those obtained for the contributions of A- and D-currents to total potassium current using pharmacological separation as in Figure 5 (see Fig. 6 caption).

\section{Variation of potassium currents with substrate: living versus nonliving astroglia}

Five substrates were compared to determine if living astroglia were required for support of the large A-currents characteristic of on-glia neurons. In these experiments, substrates were treated as described below immediately before addition of freshly dissociated hippocampal cells, and currents were recorded from neurons after 3-4 d of growth. At this time, most neurons plated directly onto coated glass will not be in contact with coplated astroglia, and thus their A-current amplitudes will be at a minimum (see below; Wu and Barish, 1992b). The substrates utilized were the following.

On-glia. Astroglial monolayers were grown from embryonic hippocampal cells following the same procedures as described
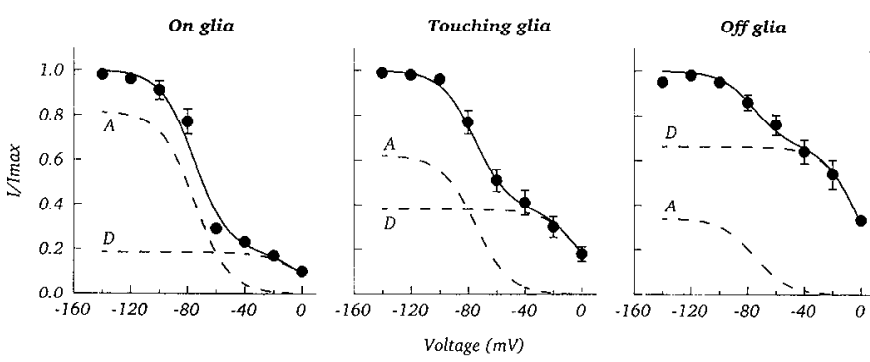

Figure 6. Voltage dependence of steady state inactivation of transient potassium currents in on-, touching-, and off-glia neurons (mean \pm SEM, $n=6$ in each category), and separation of the contributions of $\mathrm{A}$ - and D-currents to the total. In each case, the data (symbols) were fit to the sum of two Boltzmann relations representing A- and D-current. Each is indicated by a dashed line, and the sum by a solid line. Boltzmann relations were of the form $I / I_{\max }=1 /\left\{1+\exp \left[\left(V-V_{1,2}\right) / k\right]\right\}$. For each category only the relative contributions of the two Boltzmann relations to the total were varied. Boltzmann relation parameters for A-current were $V_{1 / 2}=-75 \mathrm{mV}, k=12$, and for D-current were $V_{1 / 2}=-1 \mathrm{mV}$, $k=12$. The contribution of the A-current to the total relaxing current was $0.82 \pm 0.03$ for on-glia, $0.63 \pm 0.06$ for touching-glia, and $0.34 \pm$ 0.06 for off-glia neurons (mean $\pm \mathrm{SEM}$; on-glia vs touching-glia, $p<$ 0.02 ; on-glia vs off-glia, $p<0.0001$ ). When separation of A-current was by sensitivity to conditioning depolarization (as in Figs. 4, 5), the contribution of A-current to maximum peak current was $0.73 \pm 0.03$ in on-glia neurons, while in off-glia neurons this value was $0.23 \pm 0.05$ (mean \pm SEM; numbers derived from data in Figure 5; on-glia vs offglia, $p<0.0001$ ). 

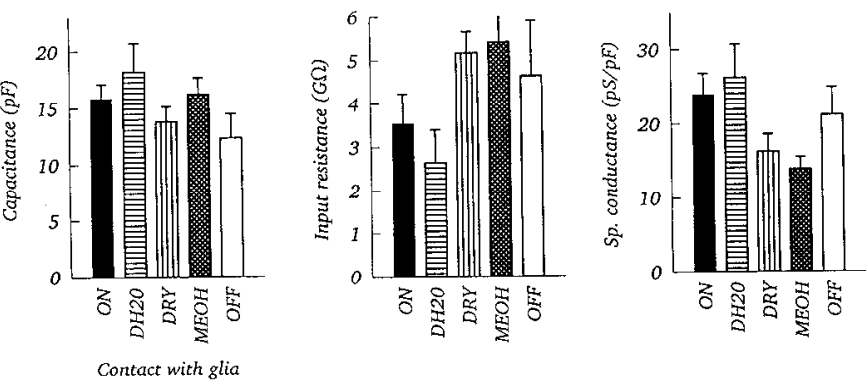

Figure 7. Variation with substrate of whole-cell capacitance, input resistance, and resting conductance density measured near the holding potential $(-80 \mathrm{mV})$. Astroglia were treated with distilled water, dried, or fixed with methanol, as described in Results. On- and off-glia preparations served as positive and negative controls. Recordings were made 3-4 $\mathrm{d}$ after dissociation and plating. Data are mean \pm SEM $(n=4-12$ cells for each category). Although trends in the data are evident (as compared to off-glia neurons, neurons on dried or fixed glial substrates may have membrane areas similar to those of on-glia neurons but have input resistances more similar to those of off-glia neurons), differences in resting electrical properties in these experiments did not reach statistical significance.

for neurons under Materials and Methods, except that mitotic inhibitors were not added until monolayers were formed. Neurons were killed by brief exposure to ice-cold medium (Huettner and Baughman, 1986). Monolayers were used after 7-10 d.

$\mathrm{dH}_{2} \mathrm{O}$-glia. Astroglial monolayers (prepared as above) were immersed in distilled water for $30 \mathrm{sec}$ to $2 \mathrm{~min}$ to release any susceptible surface components. This treatment did not lyse the glia. Cells were added after the return to normal medium.

Dry-glia. Astroglia monolayers were dried in air overnight. Cells in medium were plated directly onto the dried cells.

$\mathrm{MeOH}$-glia. Astroglia monolayers were rapidly fixed in methanol $\left(\mathrm{MeOH} ; 10 \mathrm{~min}\right.$ at $\left.-20^{\circ} \mathrm{C}\right)$ and air dried. As with dried glia, cells were plated directly onto the fixed cells.

Off-glia. Cells were plated directly onto polylysine- or laminin/polylysine-coated glass.

Neurons grown on the nonliving substrates (dry-, MeOH-,
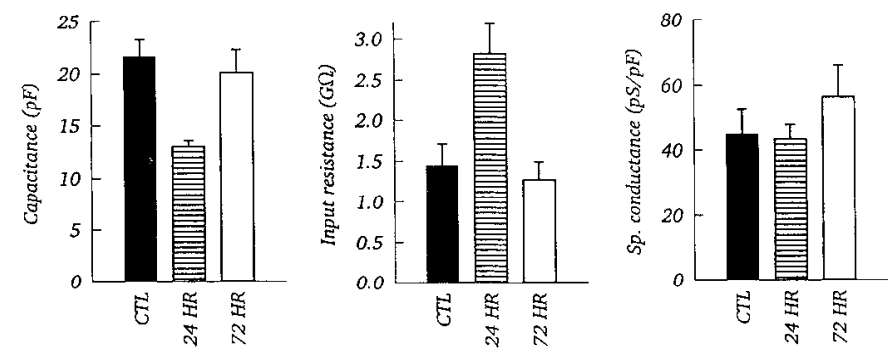

Figure 9. Effects of RNA synthesis inhibition with DRB on wholecell capacitance, input resistance, and resting conductance density measured near the holding potential. DRB $(32 \mu \mathrm{M})$ was applied $16-24 \mathrm{hr}$ (labeled $24 \mathrm{hr}$ ) or 72-84 hr (labeled $72 \mathrm{hr}$ ) after plating, and recordings were made after $5-8 \mathrm{~d}$ in culture. Measurements are mean $\pm \mathrm{SEM}, n$ $=11-34$ cells in each category. DRB affected resting properties only when applied within $24 \mathrm{hr}$ of plating; within this time window both reduction in whole-cell capacitance and increase in input resistance were significant ( $p<0.0001$ and $p<0.05$, respectively), but there was no significant change in resting input conductance density.

and off-glia neurons) tended to be smaller than those grown on the living glia (on- and $\mathrm{dH}_{2} \mathrm{O}$-glia) and to have larger input resistances (Fig. 7), although these differences did not reach statistical significance. The resting conductance densities (at -80 $\mathrm{mV}$ ) of the five classes of neurons were similar.

Analysis of potassium currents recorded from on-, $\mathrm{dH}_{2} \mathrm{O}-$, dry-, MeOH-, and off-glia neurons, and separated based on voltage dependence and pharmacology into A-, D-, and K-currents, is shown in Figure 8. Peak current amplitudes were similar for neurons grown on all substrates except coated glass (off-glia), for which they were smaller. A-current amplitudes were large for neurons on living substrates (on- and $\mathrm{dH}_{2} \mathrm{O}$-neurons), and significantly smaller in those grown on nonliving substrates (dry-, $\mathrm{MeOH}-$, and off-glia neurons). D-current amplitudes tended to be larger in neurons grown on nonliving substrates, but these differences did not reach statistical significance. When current
Figure 8. Substrate-induced variation in peak potassium current, and A-, Dand $\mathrm{K}$-currents, presented as absolute current (pA, upper row) and as current density ( $\mathrm{pA} / \mathrm{pF}$, lower row). Currents were separated based on prepulse inactivation for A-current and sensitivity to $100 \mu \mathrm{M}$ 4-AP for D-current. Data are mean $\pm \mathrm{SEM}, n=4-12$ cells in each category. Both $\mathrm{A}$-current amplitude and A-current density were significantly reduced in neurons grown on nonliving substrates (dry-, $\mathrm{MeOH}-$, and off-glia neurons) as compared to on-glia neurons $(p<0.01-0.02$ in all cases). D-current amplitude and density in neurons grown on nonliving substrates tended to be larger than those of on-glia neurons (in most instances), but these differences did not reach statistical significance except for dry-glia neurons $(p<$ 0.04 for absolute amplitude and $p<$ 0.02 for specific amplitude).
Peak current

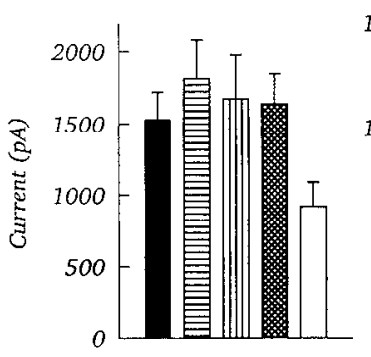

A-current
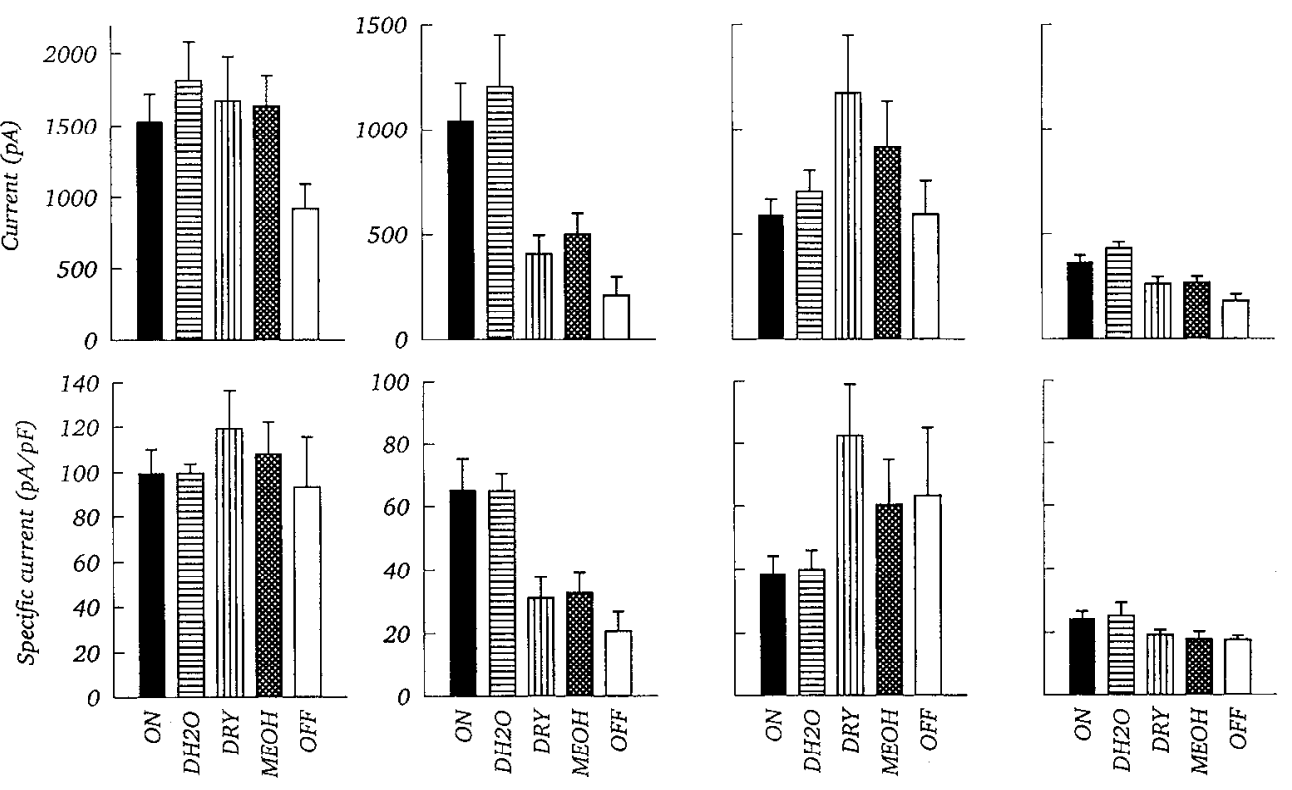

Substrate treatment 
Peak current
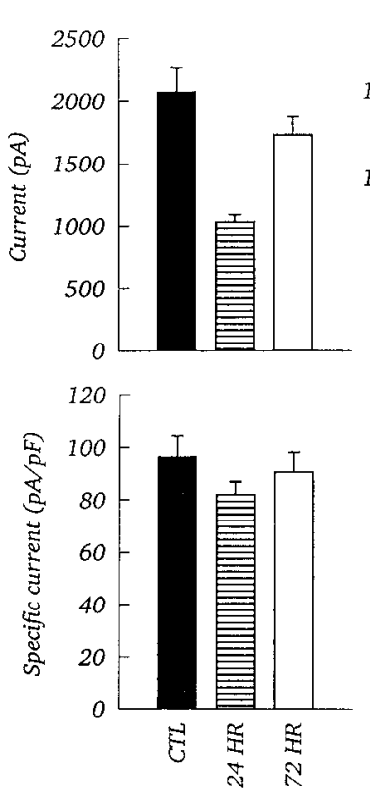

Time of DRB application
A-current
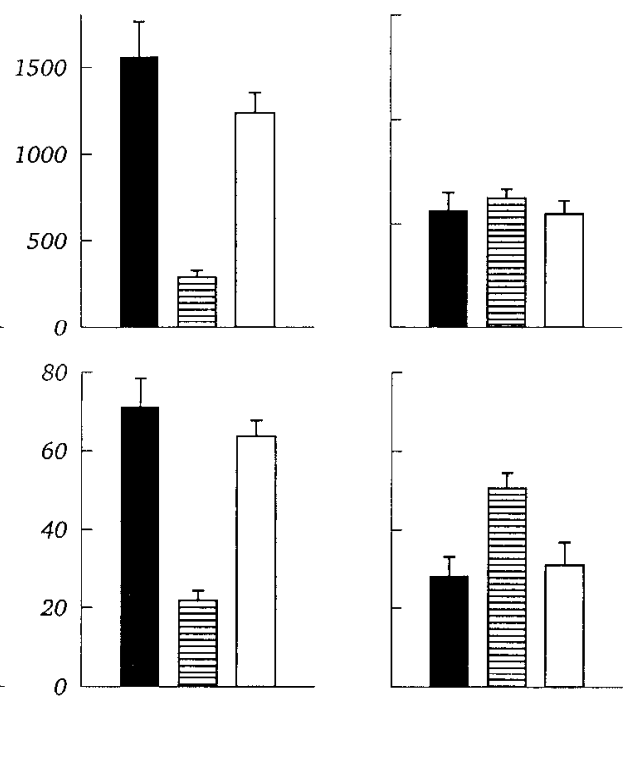

K-current

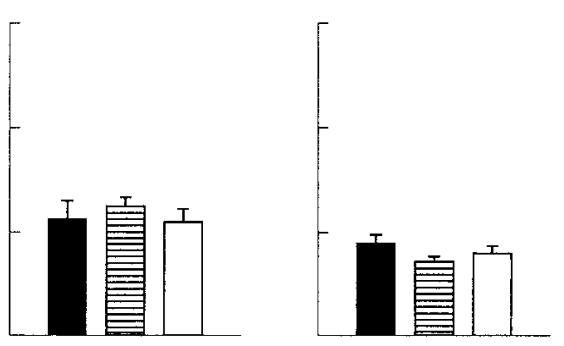

Figure 10. Effects of RNA synthesis inhibition with DRB on total potassium current, and A-, D-, and K-currents, presented as absolute current ( $\mathrm{pA}$, upper row) and as current density (pA/ $\mathrm{pF}$, lower row). DRB was applied as for Figure 9. Currents were separated based on prepulse inactivation for A-current and sensitivity to $100 \mu \mathrm{M} 4-\mathrm{AP}$ for D-current. Data are mean $\pm \mathrm{SEM}, n=$ 11-34 cells. Both A-current amplitude and $A$-current density were significantly reduced in neurons exposed to DRB during the initial $24 \mathrm{hr}$ period $(p<$ 0.0001 ), but not in neurons exposed to DRB after $72 \mathrm{hr}$. D-current amplitude was not significantly affected by DRB, but its density was increased because of the inhibitor-induced decrease in membrane area $(p<0.003)$. Neither K-current amplitude nor its density was significantly affected by DRB.

amplitudes were normalized to whole-cell capacitance, A-current density was significantly greater in neurons grown on living substrates, while D-current density tended to be larger for nonliving substrates. K-current amplitude and density appeared to be relatively unaffected by substrate.

\section{Inhibition of $R N A$ synthesis}

DRB, an inhibitor of mRNA production (Sehgal et al., 1976), was applied to the cultures to examine the possibility that the in vitro development of A-current was transcriptionally regulated. In control experiments, DRB reduced incorporation of ${ }^{3} \mathrm{H}$-uridine in mixed neuron-glia cultures to approximately $15 \%$ of control values $(n=3 ; 32 \mu \mathrm{M}$ DRB). We confirmed that in DRB-treated cultures, as in normal control cultures, the flat nonneuronal cells forming the underlying monolayer after 4-6 d in culture were GFAP-expressing astroglia (data not shown).

Pyramidally shaped neurons could be readily identified in DRB-treated cultures. When quantitative indices of membrane area and conductance were examined, on-glia neurons grown in the presence of DRB had smaller whole-cell capacitance and higher input resistance, but only when DRB was added to cultures within the first $24 \mathrm{hr}$ after plating (Fig. 9). No effects were seen when DRB was added at 72 hr or later. Resting conductance density (at $-80 \mathrm{mV}$ ) was similar for control and DRB-treated neurons regardless of when the inhibitor was applied.

DRB affected the development of potassium currents only when applied during the initial $24 \mathrm{hr}$ period, but was without effect when added after $72 \mathrm{hr}$ (Fig. 10). DRB reduced the amplitude of pcak total potassium current by selectively affecting A-current amplitude, as both D- and K-current amplitudes were similar in control and experimental cultures. As with other treatments that reduced membrane area and A-current amplitude, the net effect of DRB was to reduce A-current density and increase D-current density.

In principle DRB could have acted on glia or neurons, or both. To sort out these possibilities two complementary experiments were performed. To affect neurons differentially, normal glial monolayers were prepared, embryonic hippocampal cells were plated onto these monolayers, and DRB was added after $16 \mathrm{hr}$. To affect astroglia differentially, glial monolayers were grown in the presence of DRB, the DRB was removed, and hippocampal cells were plated onto the treated glia. In both cases potassium currents were recorded 5-8 d after addition of neurons. The results of these cxpcriments are summarized in Figure 11. For the first variant, normal glia and DRB-treated neurons, peak current density and A-, D- and K-current densities (separated based on voltage dependence and sensitivity to 4-AP) were similar in control and experimental cultures (Fig. $11 \mathrm{Al})$. Further, the numbers of cells expressing low $(<30 \mathrm{pA}$ $\mathrm{pF})$, intermediate $(30-50 \mathrm{pA} / \mathrm{pF})$, or high $(>50 \mathrm{pA} / \mathrm{pF})$ A-current densities were similar in control and experimental cultures (Fig. 11A2). In contrast, for the second variant, DRB-treated glia and normal neurons, A-current density was reduced in neurons grown on treated glia (Fig. $11 B I$ ). More significantly, the distribution of neurons showing low, medium, and high A-current densities was shifted toward lower densities (Fig. 11B2). Taken together, comparison of the results presented in Figure $11, A 2$ and $B 2$, suggests that inhibition of RNA synthesis in underlying astroglia was responsible for reduction in A-current amplitude in contacting neurons.

It is not clear why A-currents in neurons grown on the DRBtreated glia were not reduced to the same extent as when both neurons and glia were treated with DRB (as in the experiment: presented in Fig. 10). One possibility is that because the hippocampal cells added to the treated astroglia were a mixture of neurons, glia, and their undifferentiated pluripotent precursors (see Temple and Raff, 1985), neurons may have made contact with astroglia not exposed to DRB. An additional but less likely possibility is reversal of DRB inhibition after termination of astroglial exposure. Although DRB is reported to be a reversible inhibitor, we did not observe an increase in A-current amplitude after removal of DRB from cultures exposed beginning at $24 \mathrm{hr}$ after plating (data not shown). Consistent with this observation, ${ }^{3} \mathrm{H}$-uridine incorporation into glia exposed to DRB for 3 weeks increased by only $59 \%(n=2)$ after removal of DRB (data not 
Normal glia + DRB-treated neurons

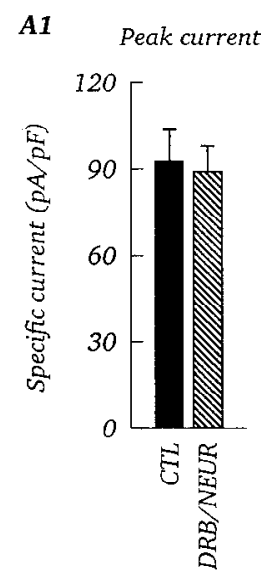

A-current

D-current

K-current
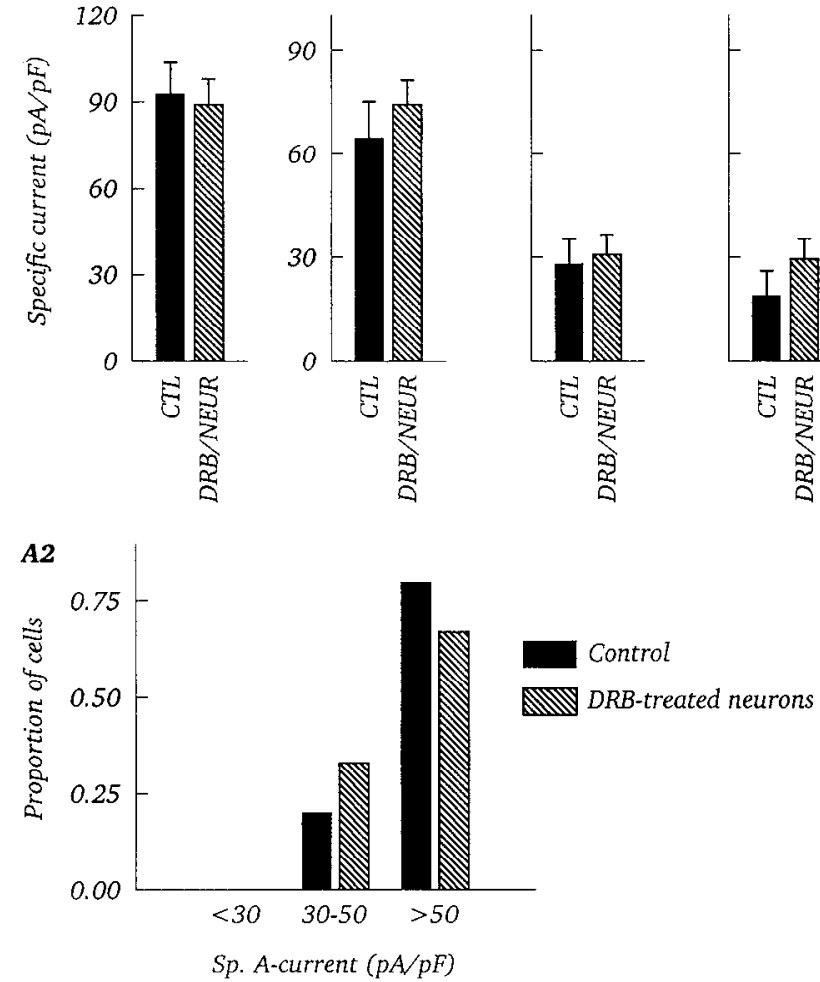

DRB-treated glia + normal neurons
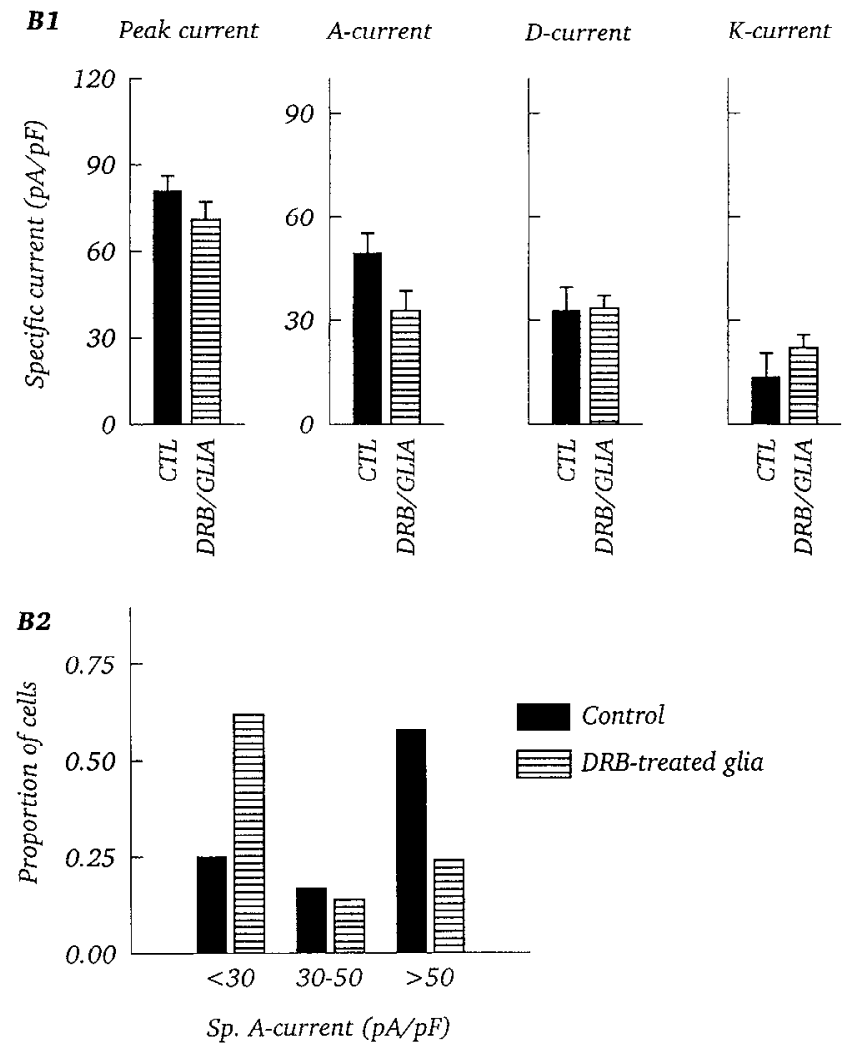

Figure 11. Effccts of sclective treatment of ncurons or of astroglial substrates with RNA synthesis inhibitor on the appearance of total potassium current, and of A-, D-, and K-currents. $A$, Potassium current densities after treatment of neurons with DRB. Cultures of normal hippocampal astroglia were allowed to form confluent monolayers (approximately $7 \mathrm{~d}$ in culture). After washing, $25 \times 10^{3}$ hippocampal cells (a mixture of neurons, glia, and undifferentiated pluripotent precursor cells) were plated onto these monolayers. DRB (32 $\mu \mathrm{M})$ was added $1 \mathrm{hr}$ after plating, and currents were recorded after $7 \mathrm{~d}$ in culture. A-, D-, and K-currents were separated based on sensitivity to conditioning depolarization or to 100 $\mu_{\mathrm{M}}$ 4-AP. Data are mean $\pm \mathrm{SEM}, n=5-6$ cells. $A 1$, Neither peak total potassium current density, nor A-, D-, or K-current densities were significantly affected by DRB treatment. $A 2$, There was no effect of DRB on the proportions of cells exhibiting low $(<30 \mathrm{pA} / \mathrm{pF})$, intermediate $(30-50 \mathrm{pA} / \mathrm{pF})$, or high $(>50 \mathrm{pA} / \mathrm{pF})$ A-current densities (same cells as in $A 1)$. B, Potassium current densities after treatment of glia with DRB. Cultures of hippocampal astroglia were exposed to $32 \mu \mathrm{M}$ DRB beginning $24 \mathrm{hr}$ after plating, and allowed to form confluent monolayers (approximately 7-10 $\mathrm{d}$ in culture). After washing, $25 \times 10^{3}$ hippocampal cells were added, and currents were recorded after 3-5 d in culture. Data are for $n=7-21$ cells. B1, A-current density was reduced in neurons grown on DRB-treated glia, but this difference was only marginally significant $(p<0.08)$. There was no significant difference in peak, D-, or K-current densities. B2, DRB treatment of glia shifted the distribution of A-current densities towards lower values along the scale of low, intermediate, or high A-current density (same cells as in $B I$ ).

shown; based on the extent of inhibition of ${ }^{3} \mathrm{H}$-uridine incorporation by DRB discussed above, one would expect complete reversal to increase ${ }^{3} \mathrm{H}$-uridine incorporation by $600-700 \%$ ).

\section{Relation between potassium currents (as affected by glial contact) and excitability}

Action potentials recorded under current clamp were affected by the presence of an astroglial substrate, as shown in Figure 12. While contact with astroglial cells may affect multiple species of ionic currents, examination of action potentials will begin to provide an indication of the relationship between transient potassium current expression and electrogenesis. The voltage- and current-clamp recordings shown were made from the same neurons. The neuron labeled on-glia exhibited substantial A-current and little D-current (upper traces). Membrane voltage recording during depolarizing current injections (middle and lower traces) showed a notch and a delay before the appearance of the first action potential. This notch reflects the activation of $\mathrm{A}$-current, as it is removed by applications of 4-AP sufficient to block A-current (as shown for the neuron labeled on-glia $(+4-A P)$; see also Connor and Stevens, 1971b). The sustained firing of this on-glia neuron reflects a balance between sustained inward current and in this case minimal D-current. In contrast, the neuron labeled off-glia exhibited only D-current, and during current injections membrane voltage reached threshold without a notch or delay. The firing of this neuron may have been truncated by activation of D-current. The neuron not exposed to DRB but grown on DRB-treated (and washed) glia (neuron labeled $D R B$-treated glia) showed minimal A-current, and a pattern of action potential generation similar to that of an offglia rather than an on-glia neuron.

\section{Discussion}

\section{Overview}

The results presented indicate that A-current amplitude in cultured hippocampal neurons was increased by contact with astroglia (Figs. 3-5). This modulation required membrane-membrane contact or other short-range interaction rather than free diffusion of a soluble factor, as currents could differ between neighboring cells on the same cover slip (Fig. 1). Variation in 
On-glia
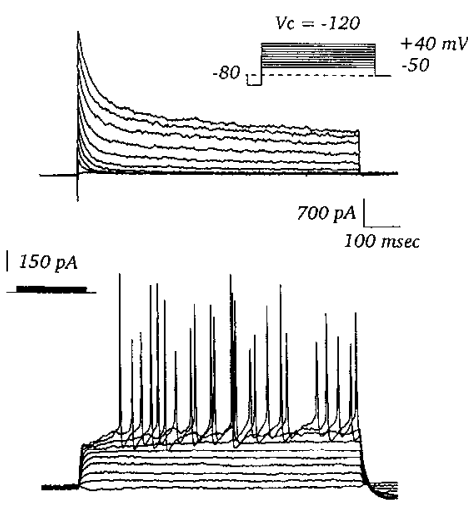

$20 \mathrm{mV}$

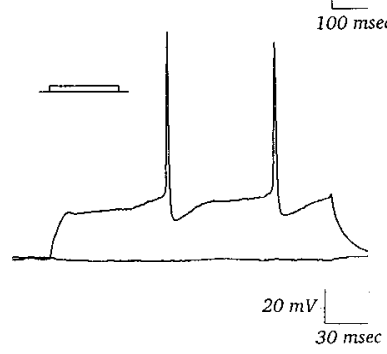

Off-glia
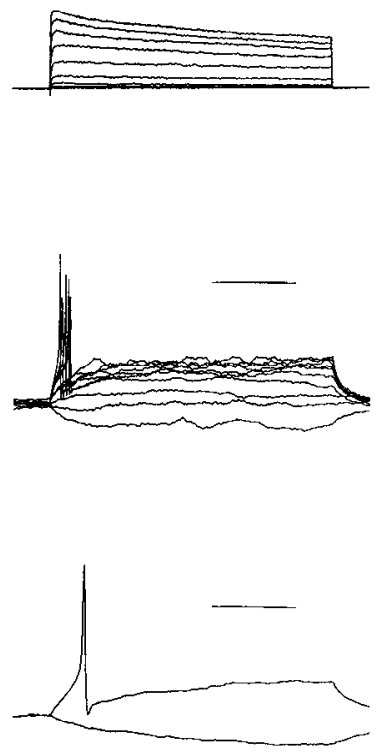

DRB-treated glia
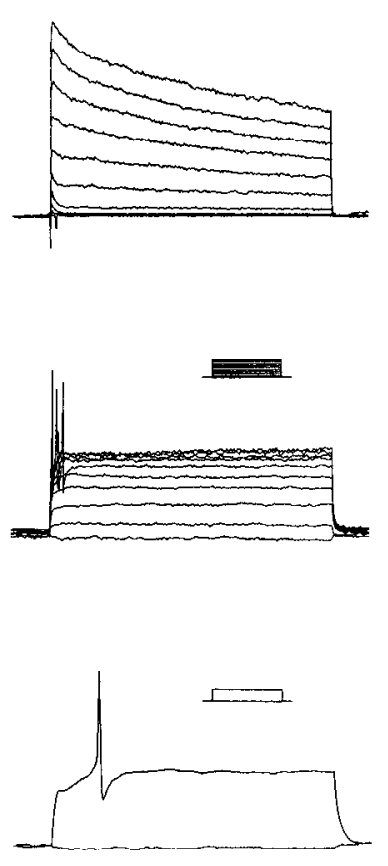

On-glia $(+4-A P)$

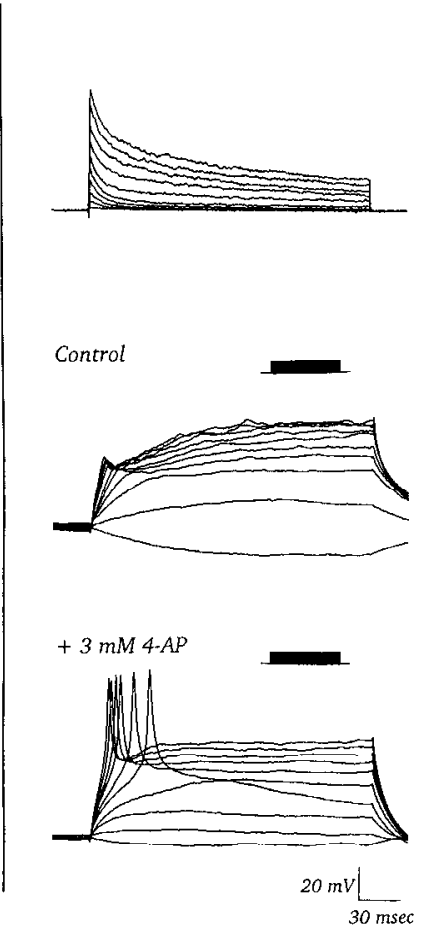

Figure 12. Variations in action potential generation related to contact with astroglial cells and the presence of A- or D-currents. Upper row, Recordings made under voltage clamp (without TTX present externally). Middle and lower rows, Current-clamp recordings made from the same neurons on two different time scales. Recordings in the first two columns were obtained from typical on- and off-glia neurons. The recording in the third column was obtained from a neuron grown on an astroglial monolayer pretreated with the RNA synthesis inhibitor DRB (32 $\mu \mathrm{M}$ for 3 weeks). The recordings in the fourth column were obtained from an on-glia neuron, and illustrate the consequences for action potential generation of A-current inhibition with $3 \mathrm{~mm}$ 4-AP. The records presented are typical of nine on-glia and six off-glia neurons studied under current clamp.

A-current was not accompanied by shifts in the voltage dependencies of activation or inactivation (Figs. 4, 6). Enhanced A-current amplitude was supported only by living astroglia, not by dried or fixed glia (Fig. 8), and could be blocked by exposure to RNA synthesis inhibitor during the first $24 \mathrm{hr}$ after dissociation and plating (Figs. 10,11). Astroglial induction of A-current was accompanied by increase in membrane area (Figs. 2, 7, 9). We conclude that astroglia express on their surface one or more factors that regulate both neuronal growth and appearance of A-type transient potassium current channels. Enhancement of A-current amplitude may occur by preferential insertion of A-channel-rich membrane, although the increases in current and capacitance may not necessarily be linked. We believe that astroglia are acting directly on neurons to influence the appearance of A-current, although we cannot exclude the possibility that the astroglia act indirectly by facilitating interactions between on-glia neurons. We suggest astroglia-to-neuron signaling and potassium current modulation as a mechanism for regulation of hippocampal neuron growth and excitability.

Modulation of transient potassium current development by non-neuronal cells may not be unique to hippocampal neurons. For chick ciliary ganglion neurons, Dourado and Dryer (1992a,b) concluded based on comparisons of age-matched acutely dissociated and cultured neurons that extrinsic factor(s) potentially derived from target cells were required for normal A-current development. For rat superior cervical ganglion neurons, McFarlane and Cooper $(1991,1992,1993)$ found that development of two forms of A-current differing in inactivation ki- netics (noted in their study as $A_{\text {fast }}$ and $A_{\text {slow }}$ ) required factor(s) present in vivo but not in cultures free of satellite cells. Further, the development of these A-current variants in culture could be influenced by non-neuronal cells. The similarity of these observations to the results presented here is striking. While the precise mechanisms of transient potassium current modulation may differ between hippocampal neurons and peripheral neurons, given the role of A-currents in establishing the repetitive firing properties of neurons, its regulation within a small region of excitable tissue by non-neuronal or target cells may be a significant mechanism for modulation of the signaling properties of groups of neurons.

\section{Differential regulation of $A$-current}

The regulation of A-current described here differs from previously described modulations of transient potassium currents in hippocampal neurons. Other studies have not separated transient potassium currents into subtypes, and have been concerned with rapid changes following neurotransmitter receptor activation or perturbations of intracellular ion concentrations (Nakajima et al., 1986; Atkins et al., 1990; Saint et al., 1990; Chen and Wong, 1991). In contrast, the regulation observed here appears to involve developmental appearance of A-currents under astroglial control, and to be associated and potentially linked to increases in neuronal membrane area.

In some instances a decrease in A-current was associated with a compensatory increase in D-current amplitude, particularly in off-glia neurons (Fig. 5) and in neurons grown on dried glia 
(Fig. 8). However, in other cases this pattern was not seen, for example, in DRB-treated neurons (Fig. 10) and in some off-glia neurons (Fig. 8). While the behavior of D-current was much more variable than that of $\mathrm{A}$-current, the data suggest reciprocal regulation of $\mathrm{A}$ - and $\mathrm{D}$-currents may occur with the absence of the signals promoting $\Lambda$-current resulting in enhancement of D-current.

\section{Nonuniform distribution of channels underlying $A$ - and D-currents}

In each of the experimental series in which A-current amplitude was regulated-on- versus touching- versus off-glia neurons, living versus nonliving glial substrates, and control versus DRBtreated cultures-contact with glial cells was associated with increased membrane area and greater than proportional augmentation of A-current amplitude. Consider, for example, the data concerned with on-, touching-, and off-glia neurons presented in Figures 2 and 5. Off-glia neurons had a mean A-current amplitude $19 \%$ of that in on-glia neurons, while mean wholecell capacitance was $70 \%$ of that of on-glia neurons. Thus, $81 \%$ of the total A-current in on-glia neurons was associated with a $30 \%$ differential in membrane area, and one possibility is that the additional $\mathrm{A}$-current was localized to this membrane. While the link of increased A-current with membrane area was not rigid-for example in one series touching-glia neurons were significantly smaller than on-glia neurons but had A-currents of similar amplitude-it was seen in the majority of cases. As morphological studies have shown that astroglia induce neurite growth in hippocampal ncurons (Noblc ct al., 1984; Fallon, 1985; Pixley et al., 1987), one interpretation of the present results is that the membrane added as a consequence of contact with astroglia may be enriched in A-current. However, an alternative hypothesis is that astroglial contact promotes insertion of both membrane and A-current channels throughout the cell, but that these are unrelated processes.

A mechanism of astroglial-induced addition of A-currentrich membrane could contribute to regional variation in hippocampal neuron excitability (Spencer and Kandel, 1961; Schwartzkroin, 1977; Wong et al., 1979; Wong and Stewart, 1992). Preferential insertion of particular types of sodium, calcium, or potassium channels in regions of dendritic, somatic, or axonal membranes has been observed (Angelides et al., 1988; Blaxter et al., 1989; Jones et al., 1989; Westenbroek et al., 1989; Ahlijanian et al., 1990; Sheng et al., 1992). Of particular interest is the observation of Sheng et al. (1992) that two potassium channel polypeptides segregate to either dendrites and somas, or to axons and terminals, of hippocampal neurons. Since the products of the mRNAs encoding the two peptides $\mathrm{Kv} 1.4$ and Kv4.2 form inactivating potassium channels when injected into Xenopus oocytes, it is tempting to speculate that the channels formed by these peptides could be those underlying the A- and D-currents described here.

\section{Consequences for hippocampal neuron excitability}

A variety of manipulations that blocked the ability of astroglial cells to support A-currents resulted in reductions of both A-current amplitude and membrane area that were accompanied by either no change or increase in D-current amplitude. When these amplitude data were normalized against membrane area (measured as whole-cell capacitance), the changes in average densities of A- and D-currents per unit membrane area became approximately reciprocal. Considered in the context of action potential generation, this pattern means that the relative contributions of A- and D-currents to overall potassium current density could vary considerably with astroglial contact. Because A- and D-currents differ in voltage dependencies and activation and inactivation kinetics (Storm, 1988; Ficker and Heinemann, 1992; Wu and Barish, 1992b), they make different contributions to the overall pattern of action potential generation. Connor and Stevens $(1971 \mathrm{a}, \mathrm{b})$ indicated that during sustained stimulation A-current would manifest itself as a delay during the slow depolarizing approach toward threshold (see also Fig. 12). In contrast, D-current is thought to have stronger effects on the width of the hippocampal action potential and on the pattern of sustained repetitive firing (Storm, 1988; Wu and Barish, 1992b). Therefore, variation in the relative proportions of the two currents in the membrane should result in changes in electrical behavior. The results presented in Figure 12 are consistent with this notion, and suggest that the extent of A-current induction by glia will influence the trajectory of voltage toward threshold while regulation of D-current will affect action potential width and repetitive firing. More detailed analyses of the effects of variation in A-current amplitude and membrane area, and of the consequences of changes in the contribution of D-current to the total potassium current wave form, will require construction of quantitative models of hippocampal neuron excitability incorporating these two distinct transient potassium currents.

\section{Conclusions}

Signals that pass from glia to neurons may involve long-range interactions cmploying solublc factors (Banker, 1980) or more short-range interactions dependent on cell-cell contact or limited diffusion of soluble factors. These glia-derived signals have multiple influences on neuronal development and functioning. During early development glia guide neuronal migration by mechanisms involving cell-cell contact (for review, see Rakic, 1981, 1990), and they are a source of multiple growth factors (for review, see Giulian et al., 1988). In mature brain, glia influence neuronal excitability by buffering extracellular potassium and amino acid neurotransmitters (for review, see Hertz, 1979; Walz, 1989), and by continued production of growth factors and cytokines active on neurons (for review, see Benveniste, 1992; Martin, 1992). Our present work further suggests that by modulating expression of transient potassium currents and the characteristics of action potential generation astroglia may influence use-dependent $\mathrm{Ca}^{2+}$ entry and accumulation in hippocampal neurons. By this mechanism glia may participate in longterm regulation of synaptic efficacy in the hippocampus.

\section{References}

Ahlijanian MK, Westenbroek RE, Catterall WA (1990) Subunit structure and localization of dihydropyridine-sensitive calcium channels in mammalian brain, spinal cord, and retina. Neuron 4:819-832.

Akins PT, Surmeier DJ, Kitai ST (1990) Muscarinic modulation of a transient $\mathrm{K}^{+}$conductance in rat neostriatal neurons. Nature 344:240242.

Angelides KJ, Elmer LW, Loftus D, Elson E (1988) Distribution and lateral mobility of voltage-dependent sodium channels in neurons. $J$ Cell Biol 106:1911-1925.

Banker GA (1980) Trophic interactions between astroglial cells and hippocampal neurons in culture. Science 209:809-810.

Banker GA, Cowan WM (1977) Rat hippocampal neurons in dispersed cell culture. Brain Res 126:397-425.

Banker GA, Cowan WM (1979) Further observations on hippocampal neurons in dispersed cell culture. J Comp Neurol 187:469-494.

Benveniste EN (1992) Inflammatory cytokines within the central nervous system: sources, function and mechanisms of action. Am J Physiol 263:C1-C16. 
Bignami $\Lambda$, Eng LF, Dahl D, Uyeda CT (1972) Localization of the glial fibrillary acidic protein in astrocytes by immunofluorescence. Brain Res 43:429-435.

Blaxter TJ, Carlen PL, Niesen C (1989) Pharmacological and anatomical separation of calcium currents in rat dentate granule neurones in vitro. J Physiol (Lond) 412:93-112.

Brown DA, Ghwiler BH, Griftith WH, Halliwell JV (1990) Membrane currents in hippocampal neurons. Prog Brain Res 83:141-160.

Chen QX, Wong RKS (1991) Intracellular $\mathrm{Ca}^{2+}$ suppressed a transient potassium current in hippocampal neurons. J Neurosci 11:337-343.

Connor JA, Stevens CF (1971a) Voltage clamp studies of a transient outward membrane current in gastropod neural somata. J Physiol (Lond) 213:21-30.

Connor JA, Stevens CF (1971b) Prediction of repetitive firing behaviour from voltage clamp data on an isolated neurone soma. J Physiol (Lond) 213:31-53.

Dourado MM, Dryer SE (1992a) Changes in the electrical properties of chick ciliary ganglion neurones during embryonic development. J Physiol (Lond) 449:411-428.

Dourado MM, Dryer SE (1992b) Extrinsic factors influence the expression of $\mathrm{K}^{+}$currents in chick ciliary ganglion neurons. Soc Neurosci Abstr 18:41

Fallon JR (1985) Preferential outgrowth of central nervous system neurites on astrocytes and Schwann cells as compared with nonglial cells in vitro. J Cell Biol 100:198-207.

Ficker E, Heinemann U (1992) Slow and fast transient potassium currents in cultured rat hippocampal cells. J Physiol (Lond) 445:431455 .

Giulian D, Vaca K, Johnson B (1988) Secreted peptides as regulators of neuron-glia and glia-glia interactions in the developing nervous system. J Neurosci Res 21:487-500.

Gustafsson B, Galvan M, Grafe P, Wigström H (1982) A transient outward current in a mammalian central neurone blocked by 4-aminopyridine. Nature 299:252-254.

Hagiwara S, Kusano K, Saito N (1961) Membrane changes of Onchidium nerve cell in potassium-rich media. J Physiol (Lond) 155:470489.

Halliwell JV, Othman IB, Pelchen-Matthews A, Dolly JO (1986) Central action of dendrotoxin: selective reduction of a transient $\mathrm{K}$ conductance in hippocampus and binding to localized acceptors. Proc Natl Acad Sci USA 83:493-497.

Hamill OP, Marty A, Neher E, Sakmann B, Sigworth F (1981) Improved patch-clamp techniques for high-resolution current recordings from cells and cell-free membrane patches. Pfluegers Arch 391:85100.

Hertz L (1979) Functional interactions between neurons and astrocytes. I. Turnover and metabolism of putative amino acid transmitters. Prog Neurobiol 13:277-323.

Huettner JE, Baughman RW (1986) Primary culture of identified neurons from the visual cortex of postnatal rats. J Neurosci 6:3044-3060.

Jones OT, Kunze DL, Angelides KJ (1989) Localization and mobility of $\omega$-conotoxin-sensitive $\mathrm{Ca}^{2+}$ channels in hippocampal CAl neurons. Science 244:1189-1193.

Kriegstein AR, Dichter MA (1983) Morphological classification of rat cortical neurons in cell culture. J Neurosci 3:1634-1647.

Martin DL (1992) Synthesis and release of neuroactive substances by glial cells. Glia 5:81-94.

McFarlane S, Cooper E (1991) Non-neuronal cells influence the expression of K currents on cultured SCG neurons. Soc Neurosci Abstr 17:778.

McFarlane S, Cooper E (1992) Postnatal development of voltage-gated $\mathrm{K}$ currents on rat sympathetic neurons. J Neurophysiol 67:12911300.

McFarlane S, Cooper E (1993) Extrinsic factors influence the expression of voltage-gated $\mathrm{K}$ currents on neonatal rat sympathetic neurons. J Neurosci 13:2591-2600.

Nakajima Y, Nakajima S, Leonard RJ, Yamaguchi K (1986) Acetylcholine raises excitability by inhibiting the fast transient potassium current in cultured hippocampal neurons. Proc Natl $\Lambda$ cad Sci USA 83:3022-3026.

Neher E (1971) Two fast transient current components during voltage clamp on snail neurons. J Gen Physiol 58:36-53.

Neumann RE, Wadman WJ, Wong RKS (1987) Outward currents of single hippocampal cells obtained from the adult guinea-pig. J Physiol (Lond) 393:331-353.

Noble M, Fok-Seang J, Cohen J (1984) Glia are a unique substrate for the in vitro growth of central nervous system neurons. J Neurosci 4:1892-1903.

Pixley SKR, Nieto-Sampedro M, Cotman CW (1987) Preferential adhesion of brain astrocytes to laminin and central neurites to astrocytes. J Neurosci Res 18:402-406.

Rakic P (1981) Neuronal-glial interaction during brain development. Trends Neurosci 4:184 187 .

Rakic P (1990) Principles of neural cell migration. Experientia 46: 882-891.

Rogawski MA (1985) The A-current: how ubiquitous a feature of excitable cells is it? Trends Neurosci 8:214-219.

Rudy B (1988) Diversity and ubiquity of K channels. Neuroscience 25:729-749.

Saint DA, Thomas T, Gage PW (1990) GABA $_{B}$ agonists modulate a transient potassium current in cultured mammalian hippocampal neurons. Neurosci Lett 118:9-13

Schwartzkroin PA (1977) Further characteristics of hippocampal CA1 cells in vitro. Brain Res 128:53-68.

Segal M, Barker JL (1984) Rat hippocampal neurons in culture: potassium conductances. J Neurophysiol 51:1409-1433.

Segal M, Rogawski MA, Barker JL (1984) A transient potassium conductance regulates the excitability of cultured hippocampal and spinal neurons. J Neurosci 4:604-609.

Sehgal PB, Damell JE Ji, Tamun I (1976) The inhibition by DRB (5,6dichloro-1- $\beta$-D-ribofuranosylbenzimidazole) of hnRNA and mRNA production in HeLa cells. Cell 9:473-480.

Sheng M, I'saur M-L, Jan YN, Jan LY (1992) Subcellular segregation of two A-type $\mathrm{K}^{+}$channel proteins in rat central neurons. Neuron 9:271-284.

Spencer WA, Kandel ER (1961) Electrophysiology of hippocampal neurons. J Neurophysiol 24:272-285.

Storm JF (1987) Action potential repolarization and a fast after-hyperpolarization in rat hippocampal pyramidal cells. J Physiol (Lond) 385:733-759.

Storm JF (1988) Temporal integration by a slowly inactivating $\mathrm{K}^{+}$ current in hippocampal neurons. Nature 336:379-381.

Storm JF (1990) Potassium currents in hippocampal pyramidal cells. Prog Brain Res 83:161-187.

Temple S, Raff MC (1985) Differentiation of a bipotential glial progenitor cell in single cell microculture. Nature 313:223-225.

Walz W (1989) Role of glial cells in the regulation of the brain microenvironment. Prog Neurobiol 33:309-333.

Westenbroek RE, Merrick DK, Catterall WA (1989) Differential subcellular localization of the $\mathrm{R}_{1}$ and $\mathrm{R}_{\mathrm{HI}} \mathrm{Na}^{+}$channel subtypes in central neurons. Neuron 3:695-704.

Wong RKS, Stewart M (1992) Different firing patterns generated in dendrites and somata of CAl pyramidal neurones in guinea-pig hippocampus. J Physiol (Lond) 457:675-687.

Wong RKS, Prince DA, Basbaum AI (1979) Intradendritic recordings from hippocampal neurons. Proc Natl Acad Sci USA 76:986-990.

Wu R-L, Barish ME (1992a) Glial modulation of transient potassium current expression in cultured mouse hippocampal neurons. Soc Neurosci Abstr 18:1501.

Wu R-L, Barish ME (1992b) Two pharmacologically and kinetically distinct transient potassium currents in cultured mouse hippocampal neurons. J Neurosci 12:2235-2246.

Zbicz KL, Weight FF (1985) Transient voltage and calcium-dependent outward currents in hippocampal CA3 pyramidal neurons. J Neurophysiol 53:1038-1058. 